\title{
Implementasi Permainan Kecil Sebagai Bentuk Pemanasan Terhadap Minat Siswa dalam Pembelajaran Pendidikan Jasamani
}

\section{Implementation of Small Games as a Form of Warming Towards Student Interest in Physical Education Learning}

\author{
Dedi Kurnia', Rama Adha Septiana² \\ 1,2 Program Studi PJKR, Sekolah Tinggi Keguruan dan IImu Pendidikan (STKIP) Pasundan, Cimahi, \\ Indonesia \\ email: wesaidyeah@gmail.com¹, ramaadha7@gmail.com²
}

doi: https://doi.org/10.20884/1.paju.2020.2.1.3302

\begin{abstract}
Abstrak
Pemanasan merupakan aktivitas penting sebelum melakukan pembelajaran inti dalam pembelajaran penjas. Namun, ketika melakukan pemanasan masih banyak siswa yang melakukannya dengan seadanya dan kadang ada yang tidak mengikutinya dengan alasan bosan dengan gerakannya. Adanya modifikasi pemanasan dengan permainan kecil perlu dilakukan agar siswa berminat untuk mengikuti pembelajaran penjas. Oleh sebab itu, penelitian ini bertujuan untuk mengetahui implementasi permainan kecil sebagai bentuk pemanasan terhadap minat siswa dalam pembelajaran Pendidikan Jasmani. Populasi sebanyak 128 kelas VIII SMPN 1 Sucinaraja, Kabupaten Garut. Sampel dalam penelitian ini adalah siswa yang berjumlah 38 siswa yang diambil menggunakan teknik cluster random sampling. Penelitian ini menggunakan metode eksperimen. Metode pengumpulan data menggunakan angket minat yang sudah diuji validitas dan reliabilitany dengan $p=0.88$. Hasil penelitian ini menunjukan bahwa terdapat pengaruh yang signifikan pada implementasi permainan kecil sebagai bentuk pemanasan terhadap minat siswa dalam pembelajaran Pendidikan Jasmani yang ditunjukan dengan uji signifikansi dengan uji T dari hasil perhitungan dapat disimpulkan bahwa $T$ tabel dengan $\mathrm{dk}(\mathrm{n}-2)=36$ yaitu 1,688 lebih kecil dari $\mathrm{T}$ hitung sebesar 434,934 (1,688 < 434,934). Modifikasi permainan kecil sebagai pemanasan harus tetap dilakukan dan diperbaharui untuk menjaga minat siswa ketika belajar penjas.
\end{abstract}

Kata Kunci : Permainan Kecil, Minat, Pemanasan, Pendidikan Jasmani

\begin{abstract}
Warming up is an important activity before doing core learning in Physical Education learning. However, when warming up there are still many students who do it improperly and sometimes some don't follow it because they are bored with the movements. The modification of heating with small games needs to be done so that students are interested in participating in Physical Education learning. Therefore, this study aims to determine the implementation of small games as a form of warm-up towards students' interest in Physical Education learning. The Population of 128 class VIII SMPN 1 Sucinaraja, Garut Regency.
\end{abstract}

Alamat Koresponden : Prodi PJKR STKIP Pasundan Cimahi

Email : wesaidyeah@gmail.com

(c) (i)

Jurnal Physical Activity Journal (PAJU) This work is licensed under a Creative Commons Attribution 4.0 International License. 
The sample in this study were 38 students who were taken using cluster random sampling technique. This research is using an experimental method. The data collection method used an interest questionnaire that had been tested for validity and reliability with $p=0.88$. The results of this study indicate that there is a significant effect on the implementation of small games as a form of warm-up on students' interest in Physical Education learning which is shown by the significance test with the T-test. smaller than $T$ count of 434,934 (1,688 $<434,934)$. Small game modifications as a warm-up must be carried out and updated to maintain student interest when learning Physical Education.

Keywords : Small Games, Interest, Warm-up, Physical Education

\section{PENDAHULUAN}

Penjas dan Olahraga adalah penggalan dari pendidikan yang selalu melibatkan dimensi sosial, sebagai objek formal ilmu keolahragaan adalah gerak laku manusia dalam bentuk gerak insani, terutama gerak yang dikuasai melalui proses belajar, gerak insani inilah yang mencerminkan puncak kreativitas manusia. Pendidikan jasmani merupakan pendidikan melalui aktivitas fisik dan permainan untuk mengembangkan potensi peserta didik (Budi, Hidayat, et al., 2019). Dalam konteks pendidikan khususnya jasmani,gerak insani inilah yang menjadi medan pergaulanan para peserta didik sebagai aktor, pendidik sebagai aktor atau pengarah, dan gerak insani inipun sebagai media interaksi dengan lingkungannya dalam upaya mencapai tujuan hidupnya. Pembelajaran Penjas di Sekolah tidak lepas dari berbagai aktivitas gerak dengan menggunakan berbagai bentuk permainan (Budi, Kusuma, et al., 2019; Nur et al., 2020). Permainan mewujudkan instrumen sebagai capaian arah dalam pendidikan jasmani untuk itu permainan dapat diberikan pada anak tanpa alat atau dengan alat (Gustiwati, 2017).

Permainan menjadi media dalam aktivitas gerak disaat pembelajaran Penjas berlangsung karena menjadi daya tarik sendiri bagi siswa dan siswi, oleh karena itu permainan dapat menjadi solusi dalam Penjas terutama saat pemanasan sebelum materi inti. Permainan yang dimaksud dalam penelitian ini adalah permainan kecil yang mana permainan kecilnya adalah model khusus dalam pemanasan. Pemanasan adalah jenjang aktivitas yang dilakukan sebelum memulai aktivitas berolahraga. Pemanasan sangatlah penting, sebelum memulai kegiatan inti dalam berolahraga, pemanasan memiliki fungsi sebagai tahapan dalam menghangatkan suhu tubuhu terutama otot, melancarkan peredaran aliran darah dan memperbanyak aliran oksigen ke dalam tubuh, memperbaiki 
Dedi Kurnia \& Rama Adha Septiana | Implementasi Permainan Kecil Sebagai Bentuk Pemanasan Terhadap Minat Siswa dalam Pembelajaran Pendidikan Jasamani

kontraksi otot dan kecepatan gerakan refleks, dan juga untuk mencegah kejang otot. (Yudanto, 2011).

Dalam melakukan aktivitas olahraga pemanasan merupakan hal yang penting, Pemanasan sendiri merupakan suatu proses yang bertujuan untuk mengadakan perubahan-perubahan psikologis dalam tubuh kita dan menyiapkan organisme di dalam tubuh dalam menghadapi aktivitas tubuh yang lebih berat, prosedur pemanasan di lakukan dengan yang ringan hingga yang berat yang mencangkup otot-otot yang akan di gunakan dalam aktivitas fisik (Kiswantoko \& Wijaya, 2018). Pemanasan bermain adalah meningkatkan minat siswa terhadap proses pembelajaran yang akan dilakukan, sehingga siswa antusias mengikuti proses pembelajaran sesudah melakukan pemanasan, siswa lebih siap untuk menerima materi yang akan diberikan, gerakan dalam pemanasan bermain sama dengan otot-otot yang akan digunakan saat materi yang akan di berikan. Pemanasan sendiri merupakan suatu proses yang bertujuan untuk mengadakan perubahan-perubahan psikologis dalam tubuh kita dan menyiapkan organisme di dalam tubuh dalam menghadapi aktivitas tubuh yang lebih berat, prosedur pemanasan di lakukan dengan yang ringan hingga yang berat yang mencangkup otot-otot yang akan di gunakan dalam aktivitas fisik (Kiswantoko \& Wijaya, 2018).

Permainan yang dimaksud pada riset ini diantaranya permainan sederhana menggunakan alat atau tanpa alat. Terdapat beberapa contoh bentuk permainan tersebut yaitu permainan kucing dan anjing, permainan lari dengan mencari kelompok, permainan tupai vs ular dan permainan sangkar burung. Permainan kecil merupakan yang menggunakan lapangan, pemain lebih sedikit, dan tidak mempunyai peraturan yang baku, baik mengenai peraturan permainan, alat yang digunakan, ukuran lapangan, maupun durasi permainan.

Bentuk permainan kecil ini menjadi alternatif menghindari kejenuhan dalam pembelajaran (Azi Faiz Ridlo, 2018). Permainan ini dirancang secara khusus untuk menumbuhkan semangat siswa dan keceriaan siswa sehingga disegani dalam pembelajaran Pendidikan Jasmani. Permainan kecil dapat di sesuaikan dengan keadaan ataupun situasi di mana dan kapan permainan yang dimaksud dilaksanakan. Dengan permainan kecil anak-anak akan mendapatkan kualitas kebugaran tubuh dan nilai-nilai atau norma yang terkandung dalam berbagai macam bentuk permainan kecil dengan pembelajaran yang lebih menyenangkan. Berbagai macam nilai yang terkandung dalam 
permaian kecil misalnya: kerjasama, tanggungjawab, menghargai teman maupun lawan, disiplin, percaya diri, keberanian, sportivitas, dan lain-lain. Dengan memberikan permainan kecil dalam pemanasan pembelajaran pendidikan jasmani dibutuhkan kreativitas atau modifikasi supaya siswa tidak merasa bosan dan jenuh, (Tanni, 2012). Permainan kecil yang ditetapkan melalui pemanasan atau materi inti salah satu upaya menghilangkan kejenuhan siswa mengikuti pembelajaran pendidikan jasmani. Melalui permainan kecil, diharapkan dapat memberikan kesiapan pada siswa terutama dari segi kondisi tubuhnya dalam mengikuti pembelajaran. Dengan begitu akan berdampak baik pada prestasi belajar siswa dan tingkat kebugaran.

Pemanasan dalam permainan kecil dapat dilakukan melalui permainan sederhana tanpa melakukan peralatan yang mengutamakan usnsur kegembiraan/menyenangkan membuat siswa lebih ceria dan berinteraksi antar siswa lainnya yang akan membuat lebih aktif. Di dalam melakukan permainan, siswa akan bergerak lari, melompat, merangkak, mendorong, mengangkat dan lain - lainnya. Gerakan - gerakan ini akan mempengaruhi terhadap kerja otot baik otot kaki, tangan, bahkan semua otot didalam tubuh manusia, seperti halnya otot jantung dan paru - paru yang berkaitan erat dengan peredaran darah dan pernafasan, (Barba-mart, Bores-garc, \& Hortigüela-alcal, 2016). Peredaran dadrah akan dipercepat yang berarti kerja jantung menjadi tambah kuat dan frekuensinya makin cepat. Pernafasan yang makin dalam ini berarti konstraksi otot paru - paru yang berhubungan dengan udara menjadi lebih banyak. Dengan demikian dapat dikatakan bahwa dengan bermain, akan mempunyai arti memperkuat otot jantung dan otot - otot pernafasan, serta meningkatkan kekenyalan organ-organ yang terkait dengan pernapasan. Dapat pula dikatakan bahwa dengan melakukan permainan,alat - alat peredaran darah dan pernapasan akan menjadi terlatih. Jantung yang terlatih akan makin memompa darah ke seluruh tubuh. Paru - paru yang terlatih akan mampu mengambil oksigen yang sebanyak-banyaknya.

Oleh karena itu awal dari saat memulai pembelajaran pendidikan jasmani sebelum memasuki materi perlu adanya modifikasi dalam melakukan sehingga dapat meningkatkan minat siswa dalam mengikuti pembelajran Pendidikan Jasmani. Bentuk pemanasan yang akan dilakukan untuk menumbuhkan minat siswa adalah dengan mengunakan bentuk permainan kecil siswa tidak akan merasa bosan atau jenuh karena akan adanya intraksi antar siswa dengan lainnya, sehingga anak mampu bekerja sama dengan temenya dalam 
Dedi Kurnia \& Rama Adha Septiana | Implementasi Permainan Kecil Sebagai Bentuk Pemanasan Terhadap Minat Siswa dalam Pembelajaran Pendidikan Jasamani

pembelajaran Pendidikan Jasmani, (Balázs, Susan, \& Henriette, 2015). Dalam penelitian ini yang dimaksud yaitu salah satu pemanasan olahraga dengan bentuk permainan kecil untuk meningkatkan minat siswa agar tidak merasa bosan dalam pembelajaran Pendidikan Jasmani. Seperti lari, kelompok untuk bermain, kerjasama tim, dan lain-lain, karena hakikatnya siswa mudah merasa bosan dalam setiap aktivitasnya sehingga akan menurunkan minat mereka dalam pembelajaran.

Minat adalah suatu perasaan yang timbul dalam diri manusia karena kemauan sendiri ataupun ajakan orang lain. Minat adalah kecenderungan dan kegairahan yang tinggi atau keinginan besar terhadap sesuatu (Budiman, 2017). Minat itu sendiri sangat penting untuk dikembangkan dalam diri siswa khususnya agar menumbuhkan semangat dalam proses pembelajaran khususnya Penjas, Rendahnya minat siswa dalam pembelajaran Penjas salah satunya disebabkan ketidakmampuan guru dalam mengelola kelas, membuat inovasi dalam pembelajaran serta menggunakan pendekatan pembelajaran yang dapat menarik minat siswa. Guru harus membuat suasana belajar yang dapat memunculkan satu keinginan yang muncul dari dalam diri siswa berupa ketertarikan terhadap kegiatan Penjas.

Minat tidak dapat dipaksakan karena akan merugikan peserta didik, sehingga peserta didik cendrung malas belajar untuk mempelajari mata pelajaran yang tak disukainya. Karena minat seseorang dapat ditumbuh dan dikembangkan pada diri sendiri tanpa adanya paksaan dari orang lain. Minat memiliki banyak efek positif pada proses dan hasil pembelajaran tingkat minat yang tinggi akan menyebabkan tingkat perhatian dan tingkat kesiapan siswa terlibat dalam objek pembelajaran sehingga menimbulkan kemungkinan keberhasilan dalam pembelajaran (Andriani \& Rasto, 2019). Dalam mencapai kebugaran jasmani dan kesehatan siswa, guru harus memberikan permainan kecil yang menarik agar siswa berminat dalam belajar. Karena minat itu sendiri adalah keinginan yang timbul dalam diri seseorang untuk memperhatikan, menerima dan melakukan sesuatu tanpa ada yang menyuruh karena sesuatu itu dinilai penting atau berguna bagi dirinya. Seperti halnya pada pembelajaran PJOK siswa diajarkan macammacam permainan kecil seperti permaian estafet bola, menjala ikan dan hitam hijau. Dalam rangka meningkatkan minat siswa pada pembelajaran PJOK (Afandi \& Hartati, 2017) 
Tujuan dari permainan kecil dalam pembelajaran Pendidikan Jasmani bagi siswa adalah untuk menumbuh kembangkan peserta didik agar tetap bugar dan sehat sehingga akan mendukung siswa dalam mengikuti pembelajaran pendidikam jasmani di sekolah. Berdasarkan paparan diatas permainan kecil memiliki keterkaitan amat penting dengan pendidikan jasmani dengan adanya unsur bermain yang sangat jelas menuntut siswa siswi untuk bermain bersama dan bekerjasama yang pada akhirnya menghasilkan interaksi antar sesama temanya yang melibatkan proses hubungan sosialisasi anak diharapkan memiliki minat dalam mengikuti kegiatan pembelajaran jasmani.

\section{METODE}

Jenis penelitian ini adalah eksperimen. Populasi disini adalah siswa kelas VIII SMP Negeri 1 Sucinaraja Kab.Garut yang berjumlah 128 siswa yang diambil dari 5 kelas. Diantaranya kelas VIII $A=25, V I I I B=26, V I I I C=28, V I I I D=24, V I I I E=24$. Teknik pengambilan sample penelitian ini menggunakan teknik Cluster random sampling dimana jumlah pengambilan sampel diundi secara random dari 5 kelas dan akhirnya didapat kelas VIII C sebanyak 28 siswa. Instrumen yang digunakan dalam penelitian ini adalah angket minat yang sudah diuji validitas dan reliabilitany dengan nilai $p=0.88$. Pengolahan data pada penelitian ini menggunakan uji t satu pihak.

\section{HASIL}

Data hasil penelitian diolah dengan menggunakan perhitungan secara manuall. Sebelum menguji nilai signifikansi, tahapan yang pertama adalah menghitung deskripsi data, selanjutnya menghitung normalitas dan menguji hipotesis dengan uji t satu pihak. Dari hasil perhitungan didapat deskripsi data dari angket minat dengan penerapan permainan kecil pada pemanasan hasil perhitungan rata-rata sebesar 152,16. Sedangkan simpangan baku sebesar 12,92 . Selanjutnya data hasil penyebaran angket diuji normalitas menggunakan pendekatan Liliefors yang akan dijelaskan pada tabel 1. 
Dedi Kurnia \& Rama Adha Septiana | Implementasi Permainan Kecil Sebagai Bentuk Pemanasan Terhadap Minat Siswa dalam Pembelajaran Pendidikan Jasamani

Tabel. 1. Hasil Data Perhitungan Uji Normalitas

\begin{tabular}{|c|c|c|c|}
\hline Variabel & $\begin{array}{c}\mathrm{L} \\
\text { Hitung }\end{array}$ & $\begin{array}{c}\text { L Tabel } \\
(38: \alpha=0.05)\end{array}$ & Keterangan \\
\hline \multicolumn{4}{|l|}{ Implementasi Permainan Kecil Sebagai } \\
\hline Bentuk Pemanasan Terhadap Minat Siswa & 0,071 & 0,143 & NORMAL \\
\hline Dalam Pembelajaran Pendidikan Jasmani & & & \\
\hline
\end{tabular}

Dari data diatas maka dapat diambil nilai harga mutlak yang paling kecil yaitu 0.071 dengan bantuan tabel nilai kritis $L$ untuk Liliefors untuk ukuran sampel sebanyak 38 dan $a=$ 0,05 maka, didapat $L$ sebesar 0.143. Oleh sebab itu Lhitung lebih kecil dari $L^{\text {tabel }}$ (Lo $=0.071<$ $L a=0.143)$, maka hipotesis diterima atau dengan kata lain dapat dirumuskan bahwa distribusi angket kerjasama tersebut "NORMAL". Data hasil perhitungan berdistribusi normal, artinya perhitungan dilanjutkan ke uji hipotesis menggunakan uji t satu pihak. Tabel 2 menjelaskan hasil perhitungan uji $\mathrm{t}$ satu pihak untuk menguji hipotesis pengaruh implementasi permainan kecil dalam pemanasan terhadap minat belajar penjas.

Tabel.2. Hasil Uji T Hipotesis

\begin{tabular}{|c|c|c|c|c|c|}
\hline Variabel & \multirow[t]{2}{*}{ Validitas } & \multirow[t]{2}{*}{ Reabilitas } & \multirow[t]{2}{*}{ t Hitung } & \multirow[t]{2}{*}{$\begin{array}{c}\text { t Tabel } \\
(\alpha=0,05: 36)\end{array}$} & \multirow[t]{2}{*}{ Hasil } \\
\hline Implementasi Permainan & & & & & \\
\hline Sebagai Bentuk & \multirow{4}{*}{0,142} & \multirow{4}{*}{0,25} & \multirow{4}{*}{434,934} & \multirow{4}{*}{1.686} & \multirow{4}{*}{ Signifikan } \\
\hline Pemanasan Terhadap & & & & & \\
\hline Dalam & & & & & \\
\hline $\begin{array}{l}\text { Pembelajaran Pendidikan } \\
\text { Jasmani }\end{array}$ & & & & & \\
\hline
\end{tabular}

Jika $\mathrm{T}$ tabel $\leq \mathrm{T}$ hitung, maka $\mathrm{H} 0$ diterima atau korelasinya tidak signifikan. Tentukan derajat bermaknaan (dk) dengan rumus $\mathrm{dk}=\mathrm{n}-2$. Dari hasil perhitungan dapat disimpulkan bahwa $T$ tabel dengan $\mathrm{dk}=38$ yaitu 1,686 lebih kecil dari pada $\mathrm{T}$ Hitung sebesar 425,614 (1.686 < 425,614) maka dapat disimpulkan bahwa Implementasi Permainan Kecil sebagai bentuk pemanasan memberikan pengaruh yang signifikan terhadap minat Siswa dalam pembelajaran Pendidikan Jasmanai di SMPN 1 Sucinaraja Garut. 


\section{PEMBAHASAN}

Hasil penelitian ini menunjukan bahwa permainan kecil berpengaruh positif terhadap minat siswa dalam mengikuti pembelajaran penjas, artinya minat siswa meningkat setelah di berikan pemanasan dilakukan melalui permainan kecil. Sejalan dengan hasil penelitian relevan yang menunjukkan bahwa terjadi peningkatan sebesar $4 \%$ pada pembelajaran dengan menggunakan permainan kecil sebagai bentuk pemanasan terhadap motivasi siswa dalam pembelajaran bolavoli (Endratmo Dwi \& Hartati, 2013).

Jadi, untuk mencapai tujuan Pendidikan Jasmani, Olahraga dan Kesehatan maka permainan merupakan salah satu bentuk alatnya, diantaranya permainan kecil. Karena Permainan kecil yang diberikan dalam pembelajaran bermanfaat bagi pembinaan keterampilan gerak maksudnya guru tidak mungkin akan memberikan pelajaran secara berkepanjangan melalui penjelasan dan penemuan saja (Sovensi, 2018). Secara karakteristik permainan kecil diadaptasi dari permainan tradisional yang ada di masyarakat. Permainan kecil adalah suatu bentuk permainan yang tidakmempunyai peraturan yang baku, baik mengenai peraturan permainannya, pemimpin permainan, media yang digunakan,ukuran lapangan, maupun durasi permainannya (Blegur, 2019)

Dengan ini menunjukkan ada pengaruh antara pemanasan tanpa menggunakan dan dengan menggunakan modifikasi permainan kecil terhadap minat siswa mengikuti pendidikan jasmani, dimana pemanasan menggunakan modifikasi permainan kecil lebih baik dibandingkan tanpa menggunakan modifikasi permainan kecil. Oleh sebab itu penulis juga menyimpulkan bahwa permainan kecil dalam pemanasan lebih besar dan meningkat pada saat melaksanakan pembelajaraan pendidikan jasmani. Strategi yang diterapkan dalam penerapan metode permainan kecil bola berantai dalam pemanasan membuat siswa menjadi lebih aktif dan antusias dalam mengikuti pembelajaran PJOK (Musitoh \& Rizal, 2018).

Temuan lain dalam penelitian ini adalah minat siswa dalam pembelajaran Penjas menjadi lebih besar dan siswa lebih tertarik akan pembelajaran Penjas. Secara umum minat dapat didefinisikan sebagai suatu perasaan, keinginan, atau kesukaan terhadap setiap kegiatan atau aktivitas pendidikan jasmani (Qohhar, Wildan.; Pazriansyah, 2019). Minat akan timbul karena adanya kebutuhan dan keinginan yang berkenaan dengan dirinya Minat siswa akan berkembang jika adanya feedback yang positif dari guru seperti pemberian 
Dedi Kurnia \& Rama Adha Septiana | Implementasi Permainan Kecil Sebagai Bentuk Pemanasan Terhadap Minat Siswa dalam Pembelajaran Pendidikan Jasamani

reward dan punishment, (Friskawati et al., 2019). Dalam pemberian permainan kecil feedback dapat diberikan kepada siswa ketika menunjukan sikap yang baik ketika bermain.

\section{SIMPULAN}

Berdasarkan hasil penelitian menunjukan bahwa Implementasi Permainan Kecil Sebagai Bentuk Pemanasan memberikan pengaruh yang signifikan. Artinya permainan kecil sebagai bentuk pemanasan berakibat pada meniningkatnya minat siswa dalam pembelajaran Penjas di SMPN 1 Sucinaraja Garut. Terdapat peningkatan skor dalam preetest ke post-test setelah pemberian treatment dalam penelitian ini sehingga terlihat jelas bahwa minat seseorang akan berubah setelah adanya pemberian hal baru dalam kegiatannya.

\section{REFERENSI}

Afandi, M. W., \& Hartati, S. C. Y. (2017). Pengaruh Permainan Kecil Terhadap Minat Siswa Dalam Pembelajaran Pendidikan Jasmani, Olahraga Dan Kesehatan Pada Siswa Kelas V Mi Nahdlatul Ulama Kecamatan Candi Kabupaten Sidoarjo. Jurnal Pendidikan Olahraga Dan Kesehatan, 5(2), 253-259.

Andriani, R., \& Rasto, R. (2019). Motivasi belajar sebagai determinan hasil belajar siswa. Jurnal Pendidikan Manajemen Perkantoran, 4(1), 80. https://doi.org/10.17509/jpm.v4i1.14958

Azi Faiz Ridlo. (2018). Pengaruh Metode Latihan Small Sided Game Terhadap Kemampuan Passing-Stopping Permainan Sepakbola. IX(2), 116-121.

Balázs, F., Susan, C., \& Henriette, D. (n.d.). Satisfaction and preferences of PE students and the head of the PE department: meeting the new curricular expectations. 11(1), 1-18. https://doi.org/10.14198/jhse.2016.111.01

Barba-mart, A., Bores-garc, D., \& Hortigüela-alcal, D. (n.d.). The Application of the Teaching Games for Understanding in Physical Education. Systematic Review of the Last Six Years.

Blegur, J. (2019). Permainan Kecil: Teori Dan Aplikasi. https://doi.org/10.31227/osf.io/dnvfe

Budi, D. R., Hidayat, R., \& Febriani, A. R. (2019). The Application of Tactical Approaches in Learning Handballs. JUARA: Jurnal Olahraga. 
https://doi.org/10.33222/juara.v4i2.534

Budi, D. R., Kusuma, M. N. H., Syafei, M., \& Stephani, M. R. (2019). The Analysis of Fundamental Movement Skill in Primary School Student in Mountain Range. https://doi.org/10.2991/icsshpe-18.2019.56

Budiman. (2017). Jurnal Olahraga. Jurnal Olahraga, 3(2), 67-74.

Endratmo Dwi, E., \& Hartati, S. (2013). BELAJAR SISWA DALAM PEMBELAJARAN PERMAINAN BOLAVOLI. 01, 562-564.

Friskawati, G. F., Widaningsih, S., \& Illahi, R. (2019). Observing student's situational interest based on the implementation of reward and punishment in physical education. Jurnal SPORTIF : Jurnal Penelitian Pembelajaran, 5(2), 198-214.

Gustiwati, R. (2017). Resty Gustiawati; Dosen Prodi PJKR FKIP Universitas Singaperbangsa Karawang 50'Tambun Selatan Kabupaten Bekasi. Riset Physical Education, 8(Vol 8 No 1 (2017): Motion: Jurnal Research Physical Education), 50-58.

Kiswantoko, D., \& Wijaya, M. R. A. (2018). Perbandingan Pemanasan Bermain Dan Pemanasan Classic ( Statis Dan Dinamis ) Terhadap Minat Dalam Pembelajaran Renang Gaya Dada Pada Kelas Viii Di Smp Negeri 3 Kota Sukabumi Tahun 2018. Seminar Nasional Pendidikan Jasmani, 1(1), 65-68.

Musitoh, \& Rizal, M. R. (2018). Pengaruh Pemanasan Menggunakan Permainan. Ibtida'i, 5(01), 161-174.

Nur, L., Malik, A. A., Juditya, S., Kastrena, E., Widyawan, D., Agustan, B., Budi, D. R., Ardha, M. A. Al, \& Yang, C. B. (2020). Comparison of two types of instruction in physical education. International Journal of Psychosocial Rehabilitation. https://doi.org/10.37200/IJPR/V24I10/PR300205

Qohhar, Wildan.; Pazriansyah, D. (2019). Physical activity journal. 1(2011), 51-60. https://doi.org/https://doi.org/10.20884/1.paju.2019.1.1.2005

Sovensi, E. (2018). Pelaksanaan Modifikasi Permainan Kecil dalam Pembelajaran Penjasorkes. Gelanggang Olahraga: Jurnal Pendidikan Jasmani Dan Olahraga (JPJO), 1(2), 96-107. https://doi.org/10.31539/jpjo.v1i2.159

Tanni, Z. A. (2012). Using Games to Promote Students 'Motivation towards Learning English Ahmed Awad Amin Mahmoud.

Yudanto. (2011). Model Pemanasan Dalam Bentuk Bermain Pada Pembelajaran Sepakbola Bagi Siswa Sekolah Dasar. Jurnal Pendidikan Jasmani Indonesia, 8(1). 